\title{
The Fine Structure of the Testis Wall in Salamandra salamandra (L.) (Amphibia, Urodela)
}

\author{
Martin Bergmann, ${ }^{1}$ Hartmut Greven ${ }^{2}$ and Jochen Schindelmeiser ${ }^{1}$ \\ Anatomisches ${ }^{1}$ und Zoologisches Institut ${ }^{2}$ der Universität Münster (Westf.), Federal Republic of \\ Germany
}

Received September 26, 1981

\begin{abstract}
Summary. In mature fire salamander testes examined in early spring, smooth muscle cells can as a rule be observed in the connective tissue which underlies the peritoneal epithelium covering the testis. These smooth muscle cells show a variable degree of differentiation that ranges from fibroblast-like cells in the cranial immature parts of the testis to contracted smooth muscle cells with bundles of myofilaments in the caudal (regressive) glandular tissue, indicating a close relationship to the spermatogenic cycle. The monolayered peritoneal epithelium consists of one cell type only, which is extremely flattened in most parts of the testis and columnar in the glandular tissue. The height of the epithelium may partly be due to the non-contracted resp. contracted state of the underlying muscle cells. The muscle cells are possibly involved in sperm discharge.
\end{abstract}

The urodelan testis consists of a various number of lobes with numerous lobules. In each lobe, successive zones of sperm development occur (i.e. spermatogonia, spermatocytes, spermatides, spermatozoa and glandular tissue) craniocaudally orientated. The general structure of the testis seems to be well documented (for review see LofTs, 1974), but the information concerning the structure of the testis wall is poor. LofTs (1974) stated in his review that "the lobules are bound together into a compact mass by connective tissue, the whole being ensheathed by a fibrous coat" (p. 139). The surrounding epithelium is characterized as "a peritoneal epithelium of columnar cells." More recent publications have particularly dealt with the ultrastructure and histochemistry of the epithelium covering the primordial germinal tissue in salamanders (e.g. Takahashi and Hanaoka, 1969; Rouy, 1974; TANaKa et al., 1980).

Regarding the considerable differences in size and structure of the discrete zones of sperm development in each lobe in the mature testis of Urodela (for S. salamandra see Joly, 1971; BERGMANN et al., 1982), differences in both the peritoneal epithelium as well as the "fibrous coat" might be expected. In continuation of our studies on the male gonad in the European fire salamander Salamandra salamandra (SchindelmeISER et al., 1981; BERGMANN et al., 1982) we here describe the testicular wall of this species including previously not described smooth muscle-like cells that underlie the peritoneal epithelium whose differentiation apparently depends on the spermatogenic cycle. 


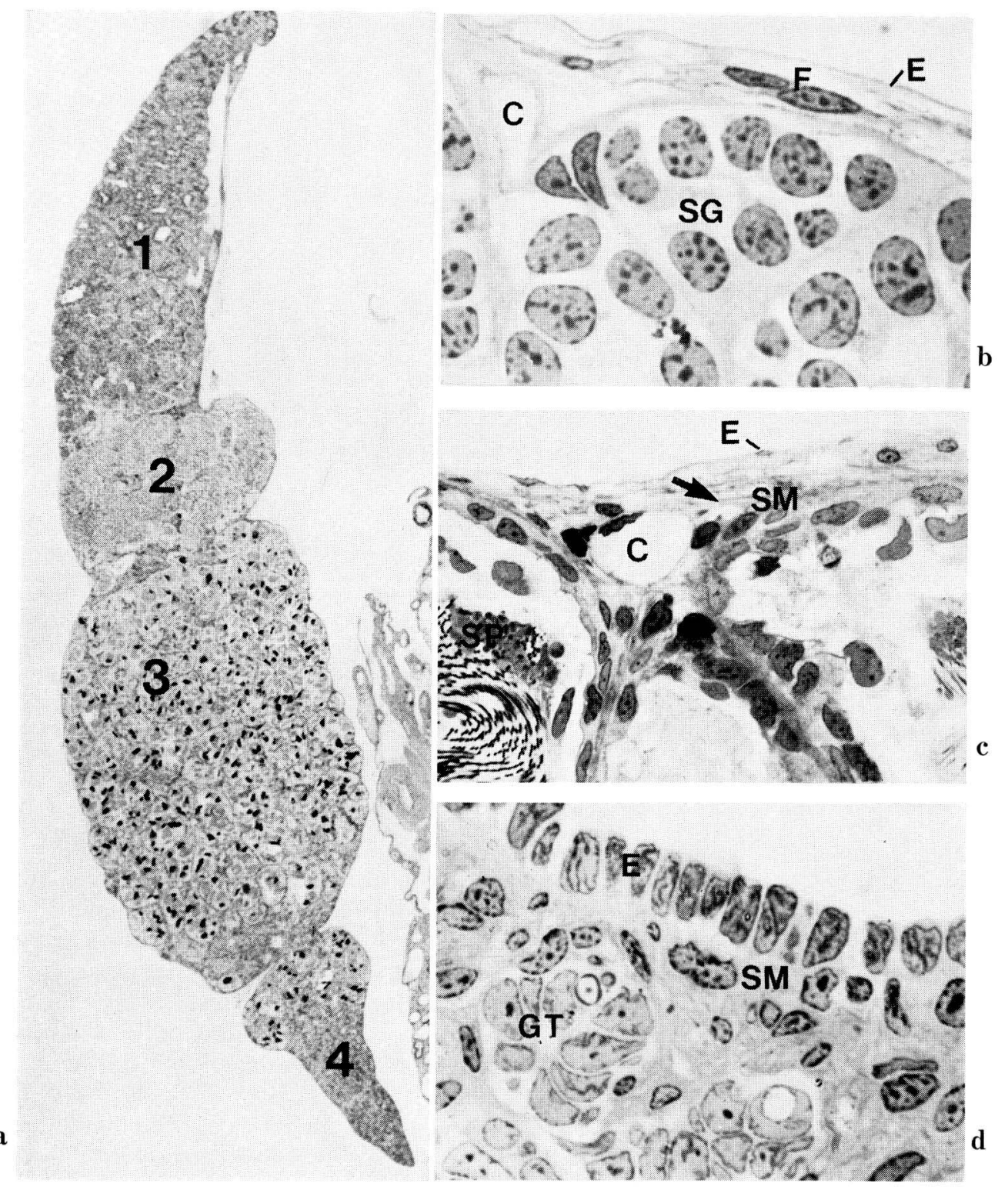

Fig. 1. Testis of Salamandra salamandra. a. Longitudinal section showing a zonation with spermatogonia (1), spermatocytes (2), spermatozoa (3), and glandular tissue (4). H.E. $\times 17$. b. Part of the testis wall in the zone of secondary spermatogonia $(S G) . \times 425$. c. Part of the testis wall in the zone of mature spermatozoa (SP) showing increasing amounts of intercellular material (arrow) in the testis wall. $\times 220$. d. Part of the testis wall in the glandular tissue (GT); note the high columnar epithelium. $\times 340$. b-d. Semithin sections, methylene blue. $E$ epithelial cells, $F$ fibroblasts, $S M$ smooth muscle cells, $C$ capillary. 


\section{MATERIALS AND METHODS}

Testes of S. salamandra, sexually mature, prepared in February, were cut into small pieces and fixed with $2.5 \%$ glutaraldehyde in $0.1 \mathrm{~mol} / 1$ cacodylate buffer at $\mathrm{pH}$ 7.3. After washing in a buffer, the tissue was postfixed in $2 \% \mathrm{OsO}_{4}$ buffered with cacodylate, dehydrated in graded concentrations of alcohol and embedded in Epon 812. Thin sections were cut on a LKB ultramicrotome, stained with uranyl acetate and lead citrate and viewed in a Philips EM 300.

\section{RESULTS}

The testis of S. salamandra was covered by a thin monolayered peritoneal epithelium of variable height in the different testicular parts examined (Fig. 1a-d). Between the epithelium and the lobule boundary cells (for terminology see LofTs, 1974) there are one or two layers of elongated fibrocyte-like cells, which craniocaudally increase in number, as well as loosely arranged collagenous fibers (Fig. 1b-d, 3a, d). The connective tissue underlying the epithelium and present between the seminiferous units (lobules) contains blood vessels (Fig. 1b, c) and occasionally nerve bundles.

The peritoneal epithelium rests upon a well developed basal lamina and consists of flattened cells in the mature and immature parts of the testis. The cells have an elongated heterochromatic nucleus with a nucleolus lacking. Irregularly arranged bundles of tonofilaments, small amounts of rough endoplasmic reticulum, microtubuli and a few mitochondria are scattered throughout the cytoplasm. Vesicles indicating exo- or endocytosis are seen in moderate numbers at the apical and the basal surfaces. The cells further possess apicolateral junctional complexes and are additionally attached to each other by small desmosomes occurring along the lateral plasmalemma. Projections of the lateral surface and widened intercellular spaces are common (Fig. 2a-d). The above described aspects can be seen in most of the testicular parts except in the primordial germinal tissue (glandular regressive tissue). Here the epithelium has become columnar, bearing a few branched microvilli-like projections on its apical surface (Fig. 2e-f).

The large oval nucleus shows prominent indentations. Endo- resp. exocytotic vesicles are frequently seen and basal processes of the cells extend deeply into the connective tissue. Other cytoplasmatic inclusions such as tonofilaments, microtubuli, mitochondria and dictyosomes appear unchanged in size and number when compared to the flattened peritoneal epithelium. Occasionally we observed large vacuoles in the cytoplasm and widened intercellular spaces (already seen light microscopically) both containing flocculent material (Fig. 2e-f, 4a).

Ultrastructural analysis of the fibrocyte-like cells underlying the epithelium reveals striking features varying, however, with the part of the testis examined.

In the immature part of the testis these cells are elongated, exhibiting all features typical for fibroblasts, i.e., a heterochromatic nucleus, a well developed Golgi apparatus (dictyosomes lying preferably near the nucleus), numerous mitochondria and a prominent rough endoplasmic reticulum. A few ribosomes are scattered throughout the cytoplasm (Fig. 3a). Parallel bundles of filaments $(6-8 \mathrm{~nm})$ can be discerned associated with dense attachments (Fig. 3b, c) already in this part of the testis wall but are more 
numerous in the deeper regions (zone of spermatocytes and zone of spermatozoa). They resemble myofilaments and dense attachments known from smooth muscle cells. The cells in the salamander testis, however, do not seem to have a distinct basal lamina and micropinocytotic activity does not appear to be frequent.

Most of the muscle cells distributed below the peritoneal epithelium ensheathing

a
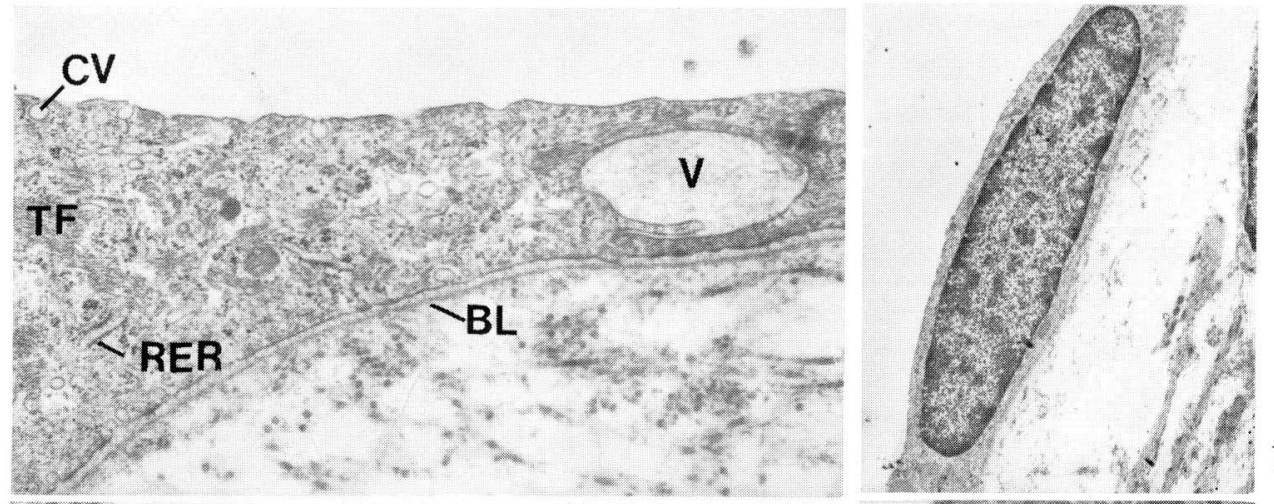

c
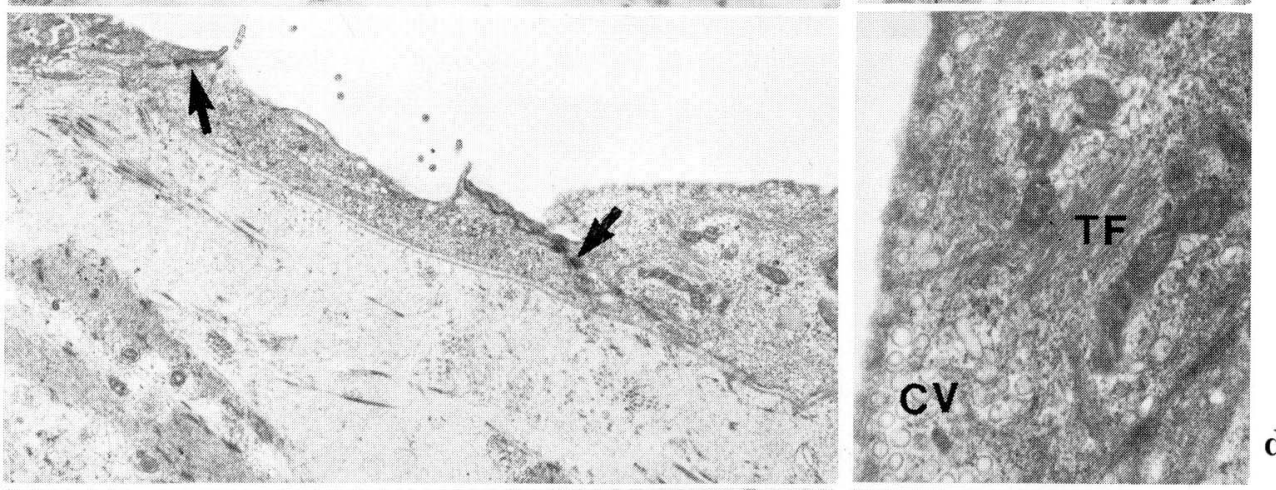

d
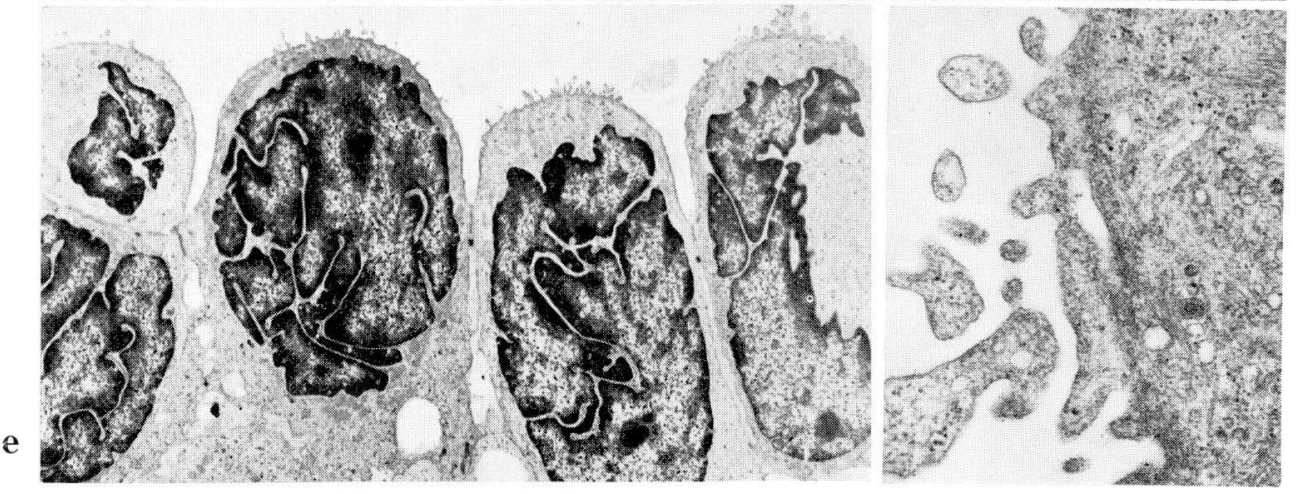

Fig. 2. Ultrastructure of the testis epithelium: $\mathbf{a}$ and $\mathbf{b}$. zone of spermatogonia, $\mathbf{c}$ and $\mathbf{d}$. zone of mature spermatozoa, e and f. zone of glandular tissue. a. Epithelial cells with cytotic vesicles $(C V)$, tonofilaments $(T F)$, rough endoplasmic reticulum $(R E R)$, basal lamina $(B L)$, note the intercellular intraepithelial vacuole $(V) . \times 16,000$. b. Nucleus-containing part of an epithelial cell. $\times 3,200$. c. Epithelial cells showing junctional complexes (arrows). $\times 7,100$. d. Detail of an epithelial cell with tonofilaments $(T F)$ and cytotic vesicles $(\mathrm{CV})$. $\times 16,700$. e. High columnar epithelial cells. Note the indented nuclei. $\times 3,000$. f. Surface enlargement (branched microvilli-like projections). $\quad \times 21,700$ 
the zone of spermatocytes and spermatozoa appear stretched and elongated (Fig. 3d), whereas in the glandular part they show a more irregular outline, with often deeply indented nuclei as well as numerous pinocytotic vesicles and dense attachments (Fig. 4).

a
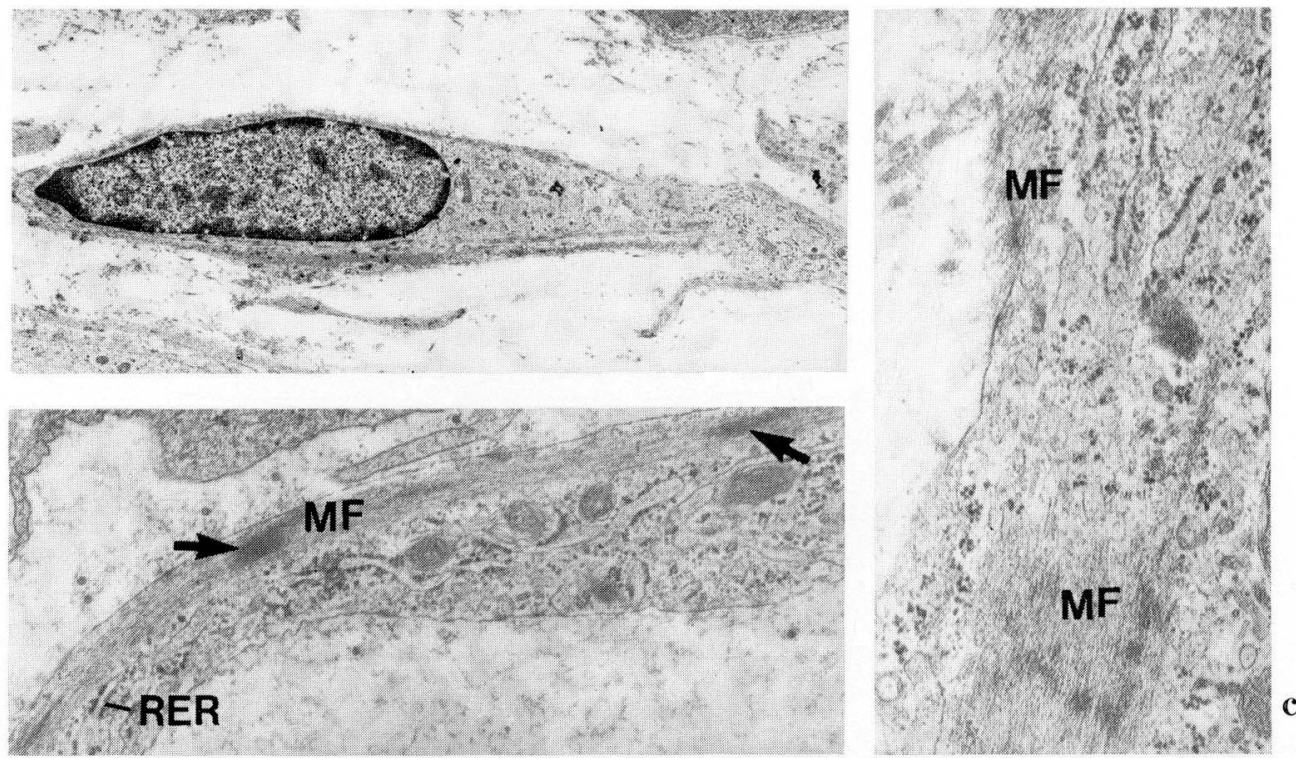

b
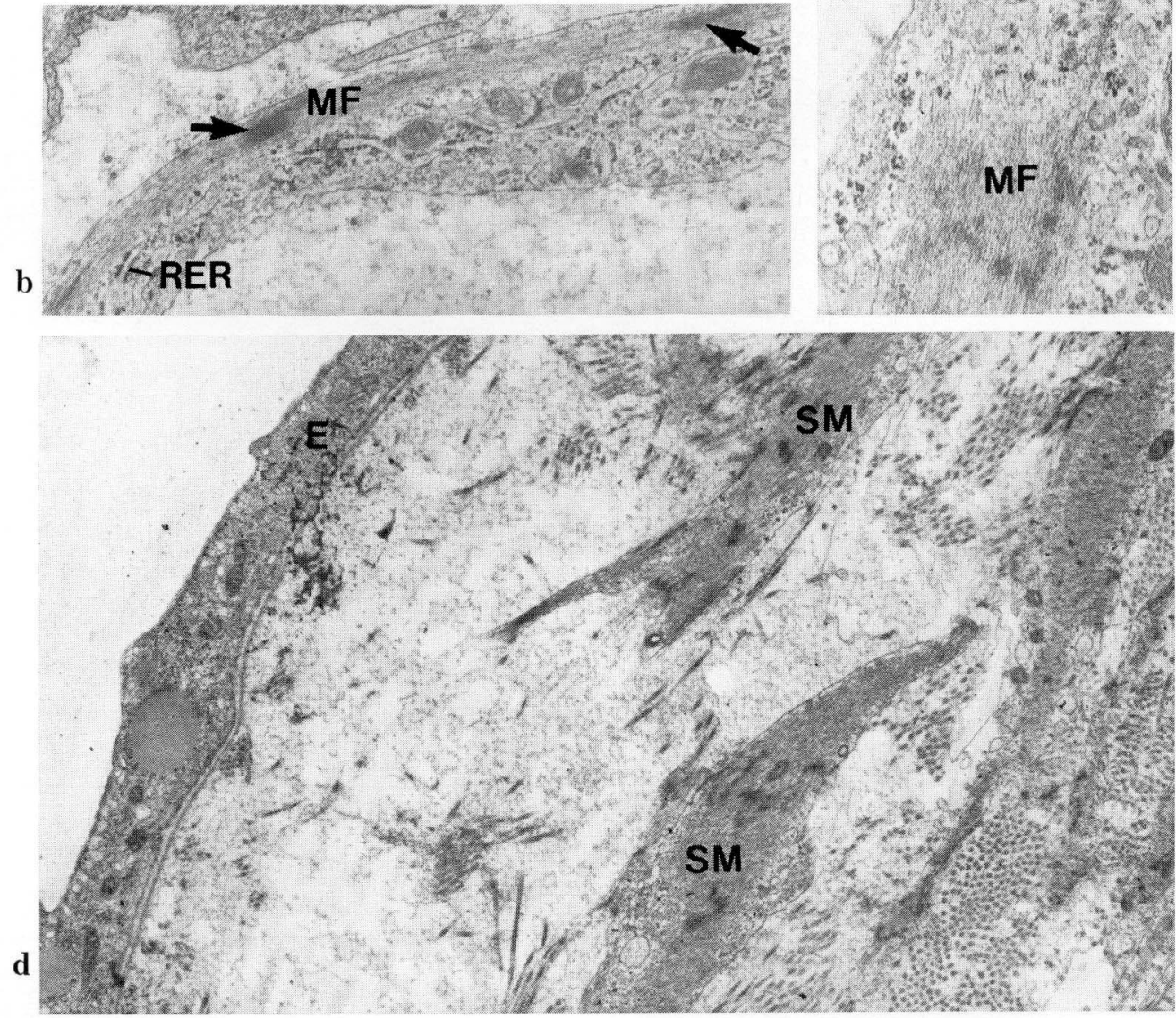

Fig. 3. Ultrastructure of the subepithelial layer of the testis wall: a-c. zone of spermatogonia, d. zone of mature spermatozoa. a. Fibroblast-like cell with some myofilaments. Note the small amounts of interstitial collagenous fibers. $\times 3,600$. b. Detail of a fibroblast-like cell with rough endoplasmic reticulum ( $R E R$ ) and marginal myofilaments $(M F)$ associated with dense attachments (arrows). $\times 17,600$. c. Enlargement of Figure 3a with marginal and central myofilaments $(M F) . \times 23,000$. d. Testis wall with typical smooth muscle cells $(S M)$. Note the increasing amount of interstitial collagenous material (cf. Fig. 1c). E epithelial cell. $\times 11,400$ 
Fibroblast-like cells and smooth muscle cells are embedded in collagenous fibers of variable length and some amorphous material which is often closely related to the fibers and probably represents immature collagen (Fig. 3d, 4). Collagenous fibers are more numerous in the glandular part.

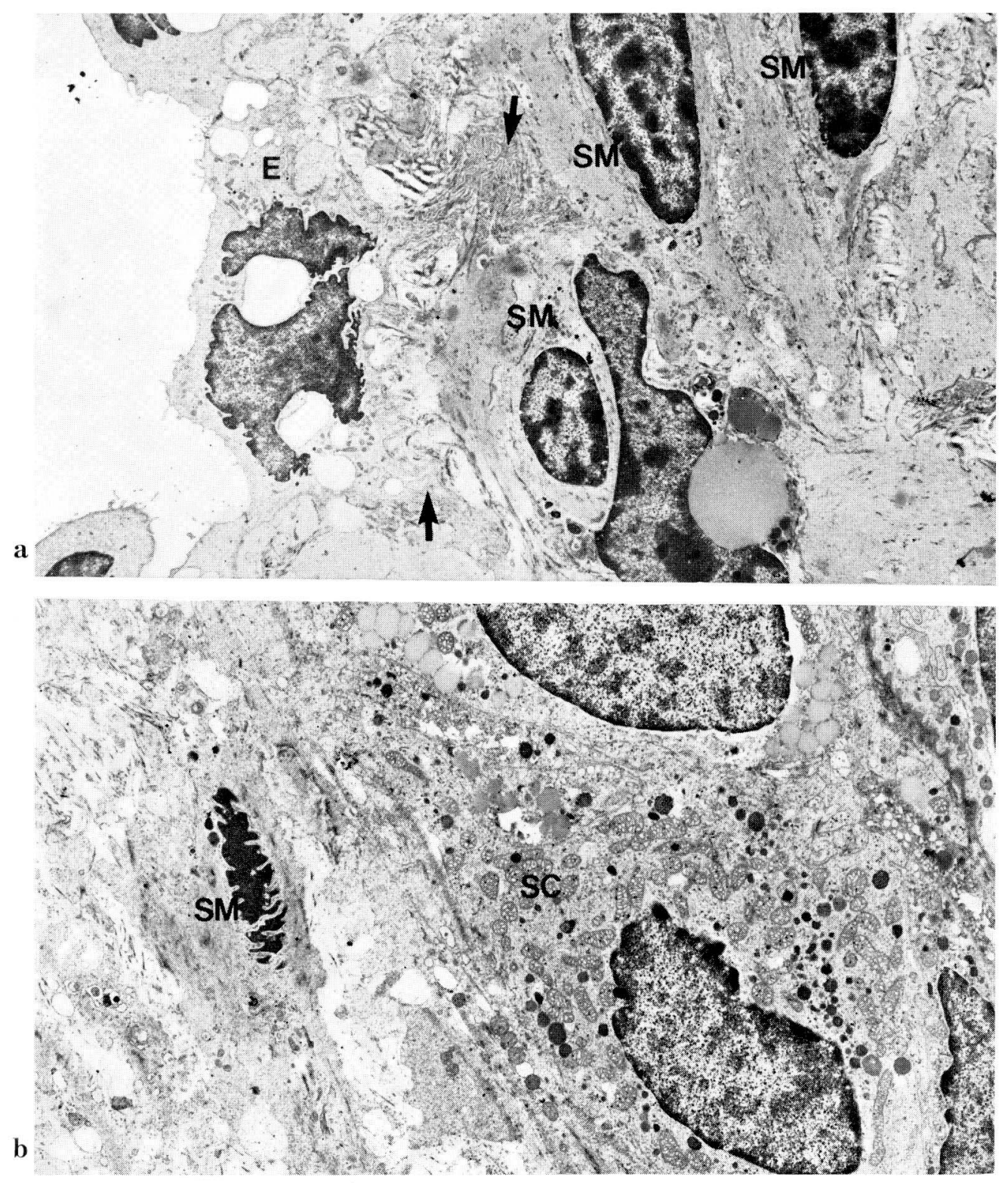

Fig. 4. Ultrastructure of the testis wall, zone of glandular tissue. a. Peritoneal epithelium (E) with deep basal infoldings (arrows); the subepithelial tissue consists of two or three layers of smooth muscle cells $(S M) . \times 2,800$. b. Contracted smooth muscle cell $(S M)$, characterized by an indented nucleus; $\mathrm{SH}$-producing cell (SC). $\quad \times 4,900$ 


\section{DISCUSSION}

Most of the papers on the testicular wall of the urodelan testis deal with the columnar epithelium covering the primordial germinal tissue (e.g. TAKaHAshi and Hanaoka, 1969; Rouy, 1974; for further readings see TANAKA et al., 1980), either supporting or rejecting the opinion that the former gives rise to the germ cells. RouY (1974), studying the ultrastructure of the columnar epithelium in several urodeles, described three cell types but denied their involvement in the germ cell line. Recently TANAKA et al. (1980) described four cell types in the columnar epithelium after treatment of Cynops pyrrhogaster with estradiol benzoate for one year. One type was very similar to primordial germ cells and/or primary spermatogonia in the normal testis. Although the discussion of the germ cell line is beyond the scope of this paper, it should be stated that in normal S. salamandra males in February, only one cell type is present in the entire peritoneal epithelium. Individual cells somewhat differ in shape and size, but this might be due to mechanical stress (see below) and/or functional demands.

Principally columnar cells in S. salamandra show no fundamental differences when compared to the main cells found in the primordial germinal tissue and the slender cord known from other urodeles (e.g. RouY, 1974; TANAKA et al., 1980).

Further, our study has shown that some of the subepithelial fibrocytes exhibit the cytological characteristics of smooth muscle cells such as parallel bundles of myofilaments $(6-8 \mathrm{~nm}$ in diameter), dense attachments associated with the bundles and the plasmalemma, and micropinocytotic vesicles (cf. KELLY and RICE, 1969). A basal lamina, however, typical for smooth muscle cells, could not be unequivocally visualized.

The structure of the muscle cells changes along the long axis of each lobe. In the upper parts, cells are flattened and do not (typical fibroblasts) or only in part (undifferentiated smooth muscle cells) show the morphological features of smooth muscle cells. In the more caudal parts they are differentiated into smooth muscle cells having numerous bundles of myofilaments. The occurrence of partially differentiated smooth muscle cells in our opinion indicates that the development of such contractile cells may be related to the maturation of the testis and, thus, may depend on the spermatogenic cycle.

Contractile smooth muscle cells have been reported also in the mammalian testis (e.g. rat: CleRmont, 1958; man: Ross, 1966), where they surround the seminiferous tubules. They are considered to play an active role in tubule movement and in sperm discharge.

The mechanism of spermiation in the anuran and possibly also in the urodelan testis is obviously mediated by a sudden uptake of fluiu (Rana temporaria, VAN OORDT et al., 1954) which can be induced experimentally by applying gonadotropin (Bufo arenarum: Houssay, 1954; Burgos and Vitale-Calpe, 1967). Water uptake causes swelling of the Sertoli cells and finally the spermatozoa are liberated by disruption of their apical cytoplasm (Tso, 1972; for review and further readings see LofTs, 1974). The presence of contractile cells in the testis wall of S. salamandra suggests that, apart from the above mentioned mode of sperm discharge, contraction of the smooth muscle cells may serve spermiation, as well as sperm movement in the efferent ductules. During or after spermiation, the muscle cells may be in a contracted state as in the glandular part; contraction may also influence the shape of the peritoneal epithelium that ranges from flat (uncontracted underlying muscles) to columnar (contracted underlying muscles). 
Acknowledgement. We are indebted to Mrs Dr. U. Beigel-Heuwinkel, Münster, for her linguistic help.

\section{REFERENCES}

Bergmann, M., J. Schindelmeiser and H. Greven: The zone of mature spermatozoa in the testis of Salamandra salamandra (L.) (Amphibia, Urodela). Z. mikrosk.-anat. Forsch. 96: 221-234 (1982).

Burgos, M. H. and R. Vitale-Calpe: The mechanism of spermiation in the toad. Amer. J. Anat. 120: 227-252 (1967)

Clermont, Y.: Contractile elements in the limiting membrane of the seminiferous tubules of the rat. Exp. Cell Res. 15: 438-440 (1958).

Houssay, B. A.: Hormonal regulation of the sexual function of the male toad. Acta physiol. latinoamer. $4: 1-41$ (1954).

Joly, J.: Les cycles sexuels de Salamandra salamandra (L.). I. Cycle sexuel des males. Ann. Sci. Nat. Zool. Paris 13: 451-504 (1971).

Kelly, R. E. and R. V. Rice: Ultrastructural studies on the contractile mechanism of smooth muscle. J. Cell Biol. 42: 683-694 (1969).

Lofts, B.: Reproduction. In: (ed. by) B. Lofts: Physiology of the amphibia. Vol. II. Academic Press, New York-London, 1974

Ross, M. H.: Contractile cells in human seminiferous tubules. Science 153: 1271-1273 (1966).

Rouy, S.: Observations cytologiques sur deux éléments caractéristiques de la structure du testicule multiple des amphibiens urodèles: spermatogonies de réserve et épithélium columnaire. Arch. Anat. microsc. 63: 183-202 (1974).

Schindelmeiser, J., M. Bergmann and H. Greven: Eine ödematöse Hodengeschwulst beim Feuersalamander, Salamandra salamandra (L.) (Amphibia, Urodela). Salamandra 17: 106-111 (1981).

Takahashi, H. and K. I. Hanaoka : Cultivation in vitro of the testis cord of the newt, Triturus pyrrrhogaster. Devel. Growth Different. 11: 186-202 (1969).

Tanaka, S., H. Iwasawa and K. Imai : Formation of germ cell-like cells in the peritoneal epithelium of the testis of estrogen-treated adult males of the Japanese red-bellied newt, Cynops pyrrhogaster pyrrhogaster. Devel. Growth Different. 22: 611-626 (1980).

Tso, C. F.: Seasonal changes in the ultrastructure and histochemistry of the newt (Triturus hongkongensis, Myer and Leviton) testes. Thesis, Faculty of Sci. Univ. of Hongkong, 1972. (Cited from B. Lofts, 1974).

Van Oordt, G. J., A. M. T. Beenakkers, P. G. W. J. van Oordt and A. M. Stadhouders: On the mechanism of the initial stages of spermiation in the grass frog, Rana temporaria. Acta endocrinol. 17: 294-301 (1954).

Dr. Martin BergmanN

Anatomisches Institut

Vesaliusweg 2-4

D-4400 Münster

Federal Republic of Germany 